\title{
A EDUCAÇÃO PARA O CONSUMO CONSCIENTE: UM COMPONENTE BÁSICO PARA A CONCRETIZAÇÃO DA EFICACIA DO DIREITO DO CONSUMIDOR BRASILEIRO
}

\author{
LA EDUCACIÓN PARA EL CONSUMO CONCIENTE: UN \\ COMPONENTE BÁSICO PARA LA CONCRETIZACIÓN DE LA \\ EFICACIA DEL DERECHO DEL CONSUMIDOR BRASILEÑO
}

\section{EDUCATION FOR CONSCIENT CONSUMPTION: A BASIC COMPONENT FOR ACHIEVING THE EFFECTIVENESS OF BRAZILIAN CONSUMER LAW}

\section{PABLO JIMÉNEZ SERRANO}

Doutor em Direito pela Faculdade de Direito da Universidade do Oriente, Cuba. Professor e pesquisador do Programa de Mestrado em Direito do Centro Universitário Salesiano de São Paulo- UNISAL. Professor e pesquisador do Centro Universitário de Volta Redonda - UniFOA. Diretor da Editora Jurismestre. Editor Responsável da Revista Direito \& Paz do Programa de Mestrado em Direito do Unisal, Lorena.

\section{REGINA CÉLIA MARTINEZ}

Mestrado e Doutorado em Direito pela Pontifícia Universidade Católica de São Paulo. Jornalista Registro Ministério do Trabalho e Emprego . Advogada, Professora Titular Doutora e Pesquisadora do Centro Universitário de Jales UNIJALES. Pesquisadora Escola Superior de Advocacia (2020) Mediadora, Conciliadora e Árbitra. Professora da Escola Paulista da Magistratura de São Paulo(EPM). Vice Presidente da Associação Paulista de Conservadores e Restauradores de Bens 
Culturais desde junho de 2015(triênio 2018-2021). Membro efetivo da Comissão de Ensino Jurídico da OAB/SP. Consultora Especialista do Conselho Estadual de Educação - São Paulo. Integrante do Banco de Avaliadores do Sistema Nacional de Avaliação de Educação Superior - BASIS. Parecerista de diversas Revistas. Consultora Jurídica.

\section{RESUMO}

Objetivo: O objetivo deste artigo é investigar o papel da educação como um elemento chave para o consumo no processo de edificação de uma consciência consumerista, tendo como pilar a edificação da eficácia social das normas do Código de Defesa do Consumidor brasileiro, abordando conceitos de consumidor, fornecedor e práticas abusivas adotadas pelos fornecedores contra consumidores.

Metodologia: A metodologia eleita foi o método dedutivo, por meio de pesquisa bibliográfica, doutrinária e normativa brasileiras acerca das relações de consumo, tendo como marcos teóricos a obra de Cavalieri Filho e de Cláudia Lima Marques.

Resultados: Concluiu-se que as práticas comerciais abusivas são imorais e opressoras, indo contra os padrões de ética da sociedade, ressaltando-se que as mesmas não necessariamente têm de produzir um dano para serem consideradas abusivas. Importa, assim, a educação dos fornecedores, que possibilite a edificação moral e a consequente informação dos consumidores sobre as empresas majoritariamente reclamadas, possibilitando, com isso, a tomada de consciência consumerista em face da não contratação de serviços e produtos dos fornecedores infratores.

Contribuições: Demonstrar a importância da educação para o consumo através da consciência sobre deveres e direitos do consumidor frente aos produtos e serviços diuturnamente ofertados pelos fornecedores, além de definir as causas dos abusos cometidos pelos fornecedores contra os consumidores, bem como destacar os aspectos que definem a correlação existente entre a negação dos direitos básicos à educação, informação e tutela jurídica em vista da eficácia do Código de Defesa do Consumidor, mesmo passados trinta anos de sua edição.

Palavras-chave: direito do consumidor; educação; informação; eficácia do direito. 


\section{RESUMEN}

Objetivo: El objetivo de este artículo es investigar el papel de la educación como elemento clave para el consumo en el proceso de sensibilización del consumidor, teniendo como pilar la construcción de la efectividad social de las normas del Código de Protección al Consumidor de Brasil, abordando los conceptos del consumidor, proveedor y prácticas abusivas adoptadas por proveedores contra consumidores.

Metodología: La metodología elegida fue el método deductivo, por medio de la investigación bibliográfica, doctrinal y normativa sobre las relaciones con los consumidores brasileños, teniendo como marco teórico el trabajo de Cavalieri Filho y Cláudia Lima Marques.

Resultados: Se concluyó que las prácticas comerciales abusivas son inmorales y opresivas, van en contra de los estándares éticos de la sociedad y enfatizan que no necesariamente tienen que producir daño para ser consideradas abusivas. Por lo tanto, la educación de los proveedores es importante, lo que permite la edificación moral y la consecuente información de los consumidores sobre las empresas en su mayoría reclamadas, lo que permite sensibilizar a los consumidores frente a no contratar los servicios y productos de los proveedores infractores.

Contribuciones: Demostrar la importancia de la educación para el consumo a través de la conciencia de los deberes y derechos de los consumidores en relación con los productos y servicios ofrecidos diariamente por los proveedores, además de definir las causas de abuso por parte de los proveedores contra los consumidores, así como destacar los aspectos que definen la correlación entre la negación de los derechos básicos a la educación, la información y la protección legal en vista de la efectividad del Código de Protección al Consumidor, incluso después de treinta años de su edición.

Palabras-clave: derecho del consumidor; educación; información; eficacia del derecho.

\section{ABSTRACT}

Objective: To investigate the role of education as a key element for consumption in the process of building a consumer awareness, having as a pillar the building of the social effectiveness of the rules of the Brazilian Consumer Protection Code, addressing consumer concepts, supplier and abusive practices adopted by suppliers against consumers.

Methodology: The deductive method, through bibliographic, doctrinal and normative 
research on Brazilian consumer relations, having as theoretical framework the work of Cavalieri Filho and Cláudia Lima Marques.

Results: It was concluded that the abusive commercial practices are immoral and oppressive, going against society's ethical standards, emphasizing that they do not necessarily have to produce harm to be considered abusive. The education of suppliers is important, which enables moral edification and the consequent information of consumers about the companies mostly claimed, making it possible to raise consumer awareness for not contracting the services and products of the offending suppliers.

Contributions: Demonstration of the importance of education for consumption through awareness of the duties and rights of consumers in relation to products and services offered daily by suppliers, in addition to defining the causes of abuse by suppliers against consumers, as well as highlighting the aspects that define the existing correlation between the denial of basic rights to education, information and legal protection in view of the effectiveness of the Consumer Protection Code, even after thirty years of its edition.

Keywords: consumer law; education; information; effectiveness of law.

\section{INTRODUÇÃO}

O Direito do Consumidor ou "Direito das Relações de Consumo" é um ramo do direito relativamente novo que estimula discussões e, consequentemente, reflexões cada vez mais aprofundadas acerca da proteção efetiva das relações jurídicas de consumo estabelecidas entre fornecedores e consumidores.

O Direito do Consumidor, mais do que um direito positivado, hodiernamente representa um microssistema que, constituído de normas: princípios e regras, almeja orientar o consumo massificado em face da defesa do sujeito mais fraco da relação tutelada: o consumidor. Trata-se, pois, de um exemplo de humanização da Justiça, no sentido de que sua aplicação exige a compreensão de seus pressupostos e fundamentos sociais, valorativos e normativos. Fala-se, assim, de um direito que não é unicamente pautado por regras ou dispositivos legais, mas que engloba valores situados acima dos interesses individuais e empresariais. 
Destarte, toda lição sobre o Direito do Consumidor deve iniciar pela educação, a informação e o conhecimento dos direitos derivados da relação consumerista em face da resolução de novos conflitos. Neste sentido, o problema da significação e da compreensão do objeto e dos objetivos do Direito do Consumidor norteia as modernas discussões que têm como base a necessidade de melhor educação para a realização da Cidadania e da Justiça.

No presente artigo, procura-se tornar possível a compreensão dos fundamentos e pressupostos que balizam a educação consumerista procurando, com isso, inibir as práticas abusivas e os conflitos que delas derivam. Neste sentido, a investigação objetiva discutir os conceitos que simbolizam o regime já instrumentalizado de resolução de conflitos nascidos das diversas práticas desenvolvidas pelas empresas e demais entes despersonalizados, com o intuito de aproximar o consumidor, seus produtos e serviços.

Procura-se, igualmente, demonstrar que existe um notável vínculo entre a falta de educação (e da informação) e a consciência consumerista. Discorre-se, assim, sobre a caracterização e resolução dos problemas que alberga este importante ramo do direito, que hoje repercute na vida de todo cidadão. De sorte que, a análise das normas, princípios e regras do Código de Defesa do Consumidor estimula na procura da sua eficiência e eficácia social.

Privilegia-se, como aspecto importante, a aplicabilidade do Código de Defesa do Consumidor: seus valores, normas e dispositivos. Por aplicabilidade, entende-se o estudo das concepções que modernamente orientam os processos de integração normativa como antessala da decisão de casos concretos, atividade própria do jurista prático.

Finalmente, destaca-se que o Código de Defesa do Consumidor merece o estudo permanente e o aprimoramento normativo constante, principalmente em relação à sua efetividade na sociedade. 


\section{O DIREITO DO CONSUMIDOR: OBJETO, NATUREZA E OBJETIVOS}

O Direito do Consumidor ou Direito do Consumo é definido como um conjunto de princípios e regras destinados à proteção do consumidor; verifica-se, desde logo, não ser o consumo, enquanto tal, o objeto da tutela das regras que constituem este novo ramo do direito, mas, sim, o próprio consumidor. Este instrumento normativo serve para disciplinar a produção e a distribuição de bens, assim como a prestação de serviços, tendo em vista a defesa do consumidor. Em outras palavras, é sobre o fornecedor de produtos e serviços que recaem obrigações de várias espécies em ordem à defesa do consumidor. A preocupação não está focada no objeto de alguma relação jurídica (enfoque objetivo), mas em um sujeito (enfoque subjetivo). (CAVALIERI FILHO, 2011, p. 8)

No mesmo sentido, Claudia Lima Marques (2010, p. 29-31) define o Direito do Consumidor como um ramo novo do direito, disciplina transversal entre o direito privado e o direito público, que visa proteger um sujeito de direitos, o consumidor, em todas as suas relações jurídicas frente ao fornecedor, um profissional, empresário ou comerciante. Assim, explica a citada autora, trata-se de um conjunto de normas e princípios especiais que visam cumprir com um triplo mandamento constitucional, a saber, promover a defesa dos consumidores (art. 5‥, inciso XXXII, da Constituição), assegurar, como princípio geral da atividade econômica, a defesa do consumidor (art. 170 da Constituição) e sistematizar e ordenar a tutela especial infraconstitucionalmente, por meio de uma microcodificação, o Código de Defesa d Consumidor, art. 48, do Ato das Disposições Constitucionais Transitória da Constituição de 1988.

De acordo com Leonardo de Medeiros Garcia (2010, p. 8), o Direito do Consumidor é um microssistema jurídico, em que o objetivo não é tutelar os iguais, cuja proteção já é encontrada no Direito Civil, mas justamente tutelar os desiguais, tratando de maneira diferente o fornecedor e o consumidor, com o fito de alcançar a igualdade.

Para Leonardo Roscoe Besa (2010, p. 316), um tema ao qual o Código do Consumidor dedica especial atenção é a proteção contratual do consumidor. $\mathrm{O}$ 
objetivo legal é promover a lealdade, a transparência e o equilíbrio nas relações entre o fornecedor e o consumidor.

$\mathrm{Da}$ análise dessas e de outras definições parece surgir uma divergência quanto ao sentido e ao alcance desta disciplina. Trata-se de saber se ela existe para proteger unicamente o consumidor ou se também suas normas abrangem as relações de consumo. Com o intuito de superar essa dificuldade e devido à complexidade do seu objeto, prefere-se denominar a disciplina da seguinte forma: "Direito das Relações de Consumo". Em verdade, esta opção não é pacífica, mas há de se entender como um pilar importante que permitirá superar inúmeros equívocos doutrinários quanto ao sentido e ao alcance deste microssistema. Falar-se-á, pois, do seu sentido e alcance, não sem antes se referir a algumas definições, aqui consideradas como ponto de partida importante para a compreensão de sua natureza e objeto.

Pode-se concluir que o Direito do Consumidor é um sub-ramo do Direito constitutivo de um conjunto de teorias, normas e práticas jurídicas que objetivam a tutela das relações consumeristas, a educação para o consumo, a previsão e a resolução de conflitos. Assim, limita-se a significar o Direito do Consumidor da seguinte maneira: o Direito do Consumidor é uma disciplina jurídica constituída de um conjunto de pressupostos teóricos (conceituais e valorativos), e normativos (princípios e regras) destinadas à tutela das relações jurídicas de consumo, constituídas pelos sujeitos consumidor e fornecedor.

Para CAVALIERI FILHO (2011, p.7),

[...] à medida que o fornecedor se fortaleceu técnica e economicamente, o consumidor teve o seu poder de escolha enfraquecido, praticamente eliminado, desta forma houve o desequilíbrio, que gerou a vulnerabilidade tríplice, que é a vulnerabilidade fática, técnica e jurídica, com isso foi-se necessário que se crie um código que elimina-se o desiquilíbrio para que consumidor possa atuar no mercado tendo ciência de seus direitos, com a informação e garantia de que será tutelado, caso seja necessário.

Com as mudanças vividas no último século, a sociedade mudou de tal forma, que foi necessário garantir os direitos dos consumidores, pois eles são a 
parte maior e principal da relação de consumo, mesmo não sendo valorizada pelos fornecedores.

Mesmos nos dias atuais, com toda a evolução e criação de uma legislação que proteja o consumidor, ainda os consumidores encontram uma grande dificuldade em ir contra os fornecedores; com todas essas dificuldades os fornecedores continuam praticando abusividades em face do consumidor.

Ao definir-se a natureza do Direito do Consumidor, autores dividem-se. Eis que, para alguns, as regras jurídicas reguladoras das novas relações de consumo constituem um Direito Social; para outros, o regime consumerista pode ser visto como uma ramificação do Direito Civil, também vinculado ao Direito Empresarial, Constitucional, Penal e Administrativo, entre outros, e referido mais à proteção dos direitos coletivos do que dos individuais, por ser o resultado das conquistas obtidas dentro das lutas de classes sociais. A doutrina consumerista é pacífica em aceitar que o Código de Defesa do Consumidor é uma norma de ordem pública. Assim, "as normas contidas no Código de Defesa do Consumidor são de ordem pública e de interesse social, sendo, portanto, cogentes e inderrogáveis pela vontade das partes" (GARCIA, 2010, p. 8). Destaca-se, neste sentido, que o Supremo Tribunal de Justiça já se manifestou:

CÓDIGO DE DEFESA DO CONSUMIDOR. NORMA DE ORDEM PÚBLICA. DERROGAÇÃO DA LIBERDADE CONTRATUAL. O caráter de norma pública atribuído ao Código de Defesa do Consumidor derroga a liberdade contratual para ajustá-la aos parâmetros de lei (...) (STJ, Resp. 292942/MG, Rel. Min. Sávio de Figueiredo Teixeira, DJ 07/05/2001)

A primeira questão a ser destacada é o sentido humanístico implícito no princípio da dignidade da pessoa humana como bem intangível.

Promover significa assegurar afirmativamente que 0 Estado realize positivamente a defesa, a tutela dos interesses destes consumidores que, como vimos é um direito fundamental (direito humano de nova geração, social e econômico) a uma prestação protetiva do Estado, a uma atuação positiva do Estado, por todos os seus poderes: Judiciário, Executivo, Legislativo". (MARQUES, 2010, p. 30) 
Por conta da natureza difusa do Direito do Consumidor, alguns autores apontam seu caráter social (é Direito Social), a sua origem privada ou privatista (é uma continuação do Direito Civil e, mais especificamente do Direito Empresarial), ou tem origem constitucional. Mas, verdadeiramente, as normas contidas no Código de Defesa do Consumidor são de ordem pública e interesse social. Diz-se de um direito fundamental (de terceira geração), direito humano de nova geração, social e econômico. (GARCIA, 2010, p. 8)

Diz-se da defesa dos direitos ou interesses legítimos individuais, mas também coletivo e social típico das sociedades capitalistas industrializadas, onde os riscos do progresso devem ser compensados por uma legislação tutelar e subjetivamente especial. Trata-se, conforme diretrizes da Organização das Nações Unidas, de um direito humano de nova geração (ou dimensão), um direito social e econômico, um direito de igualdade material do mais fraco, do leigo, do cidadão civil nas suas relações frente aos fornecedores de produtos e serviços que nesta posição são experts, fortes ou em posição de poder. (MARQUES, 2010)

Pode-se afirmar, então, que o regime jurídico consumerista respeita a hierarquia constitucional, assim "a garantia constitucional de proteção e defesa do consumidor é considerada cláusula pétrea, impossível de ser suprimida ou restringida pelo legislador". (GARCIA, 2010, p. 11)

Em suma, considera-se ser um ramo de direito tutelar, "social", difuso e coletivo que, evidentemente, guarda relação com outros ramos e disciplinas, fundamentalmente com o Direito Constitucional, o Direito Civil, Administrativo, Penal e Processual. Portanto, considera-se que a sua natureza é difusa.

O Direito do Consumidor tem como matéria ou assunto a tutela dos interesses próprios dos sujeitos que participam da relação consumerista: fornecedor - consumidor, tentando, assim, minimizar as desigualdades, inibir as agressões e os abusos dos quais o consumidor é vítima, mas também definir as causas excludentes de responsabilidade, procurando, com isso, restabelecer a boa-fé e o equilíbrio contratual na relação de consumo. 
Assim, insiste-se na ideia de que o Direito do Consumidor desempenha um papel decisivo na nova regulamentação das relações jurídicas surgidas da contratação em massa. Este Direito, tão especial, nos dias atuais apresenta-se como resultado do movimento internacional de defesa do consumidor, que começou a fazer-se sentir em todo o mundo.

Em verdade, o Direito das Relações de Consumo assenta-se no Código de Defesa do Consumidor:

[...] regulamento de alta proteção ao consumidor nas sociedades capitalista contemporânea, com regras específicas muito bem colocadas e que acaba gerando toda a sorte de dificuldade de interpretação das questões contratuais, da responsabilidade, da informação, da publicidade, do controle in abstrato das cláusulas contratuais, das ações coletivas, enfim, literalmente de tudo o que está por ele estabelecido. (NUNES, 2011, p. 3940)

Decerto, para satisfazer suas necessidades, os cidadãos necessitam estabelecer relações contratuais. Esses contratos têm como causa as atividades relacionadas com a criação - denominada trabalho -, que pressupõe o desenvolvimento.

É ponto pacífico que o trabalho como atividade humana permite que o homem aproprie-se das riquezas das coisas que brinda a natureza, para transformálas em bens e satisfazer, desta maneira, suas necessidades. O processo de trabalho inclui a atividade racional do homem, pela qual se transmitem as mercadorias desde o produtor ao consumidor, desde o proprietário ao proprietário ou possuidor, e se obtém os serviços em geral. Portanto, utiliza-se o contrato de consumo como uma instituição econômica e jurídica que se manifesta em todas as esferas da atividade socioeconômica e, mais ainda, na atividade artística, profissional, industrial e trabalhista.

Quanto aos objetivos: o télos, a teleologia ou o para quê do Direito do Consumidor? e, de acordo com a opinião comum dos doutrinadores, considera-se que 0 Direito do Consumidor tem por finalidade tentar minimizar as desigualdades socioeconômicas e jurídicas existentes entre o fornecedor e o consumidor e inibir e 
sancionar as agressões e abusos dos quais o consumidor é vítima, procurando, com isso, restabelecer um equilíbrio contratual na relação de consumo.

Quer-se dizer, com isto, que a abordagem dos diversos temas vinculados ao Direito do Consumidor permite avaliar o nível de profundidade e atualidade com que se vem tratando do assunto na comunidade jurídica nacional e internacional. No entanto, qualquer enfoque histórico ou legislativo sobre o Direito do Consumidor introdu-lo no mundo heterogêneo de suas regras e no importante estudo das regulamentações estabelecidas pelos legisladores na maioria dos Estados; portanto, a nosso ver, é meritório ressaltar os benefícios que qualquer estudo científico, desenvolvido sobre o assunto, brinda ao ordenamento jurídico internacional.

Todo ensinamento do regime jurídico consumerista, em princípio, há de servir para:

Primeiro: possibilitar a compreensão objetiva da evolução e 0 desenvolvimento deste importante direito (Direito do Consumidor);

Segundo: verificar o nível de aproximação e diferenças existentes entre o Direito privado e o Direito do Consumidor;

Terceiro: avaliar a concretização ou efetiva proteção das complexas relações de consumo;e

Quarto: contribuir para a resolução dos conflitos que de tais relações derivam-se.

Em suma, o estudo da disciplina e a apreensão do seu regime jurídico permite compreender, primeiro, as bases ou estrutura do consumo em massa (objeto) e, segundo, a necessidade da sua proteção (objetivos) como resultado do efeito negativo da produção seriada, própria da sociedade capitalista contemporânea. 


\section{PRÁTICAS COMERCIAS ABUSIVAS}

Definem-se as práticas abusivas como um conjunto de ações desenvolvidas pelos fornecedores em desconformidade com os padrões mercadológicos de boa conduta em relação ao consumidor. Trata-se, pois, de um conjunto de atividades que, por serem enganosas, tornam-se abusivas e ferem as bases (fundamentos) da ordem jurídica (a boa-fé e os bons costumes). Assim, por exemplo, a prática abusiva seria o gênero e a publicidade abusiva a espécie. Todavia, a prática abusiva não se confunde com a concorrência desleal. A primeira dá-se no plano vertical (relação fornecedor - consumidor); e a segunda no plano horizontal (relação fornecedor fornecedor). (BENJAMIN, 2010, p. 251/252)

Como se pode observar, a prática abusiva dá-se pelo uso inadequado ou negativo das práticas comerciais, isto é, dos mecanismos, técnicas e métodos pósprodução de colocação de produtos e serviços no mercado. Como bem afirma Herman Benjamin (2004, p. 242), nelas estão incluídas: o marketing (ofertas, promoções, condições de negociações e publicidade, entre outros), as garantias, os serviços pós-venda, os arquivos de consumo e as cobranças de dívidas. Contudo, as práticas comerciais abusivas são condutas desleais que acarretam vantagens desproporcionais em favor do fornecedor, as quais desestabilizam a harmonização e o equilíbrio dos interesses dos participantes nas relações consumeristas (consumidor e fornecedor de produtos e serviços), princípio basilar da Política Nacional das Relações de Consumo, insertas pelo Código de Defesa do Consumidor (art. 6․ do CDC).

As práticas abusivas são, conforme explica Rizzatto Nunes (2005, p. 512):

[...] ações e/ou condutas que, uma vez existentes, caracterizam-se como ilícitas, independentemente de se encontrar ou não algum consumidor lesado". Assim, por exemplo, mesmo que o consumidor fique satisfeito por ter recebido em casa um cartão de crédito sem ter pedido, essa aceitação não elide a abusividade da prática. 
Diz-se, assim, do abuso do direito como o resultado do excesso de exercício de um direito, capaz de causar dano a outrem. Ou, em outras palavras, o abuso do direito caracteriza-se pelo uso irregular e desviante do direito em seu exercício, por parte do titular. (NUNES, 2005, p. 510)

Em suma, nas relações de consumo há muitas formas de abusos praticados por fornecedores de produtos e serviços e que geram dano moral. As práticas abusivas, em geral, são prescritas nos artigos 39, 40 e 41 do Código de Defesa do Consumidor. Elas podem ser classificadas da seguinte maneira: a) pré-contratuais e; b) pós-contratuais.

\subsection{PRÁTICAS ABUSIVAS PRÉ-CONTRATUAIS}

As práticas abusivas pré-contratuais, como sua denominação indica, são aquelas praticadas (originadas) muito antes da existência de um contrato (consentimento contratual) e estão implícitas na oferta vinculante que também irá ser estudada nesta obra. Veja-se alguns exemplos.

a) Venda casada: condicionar o fornecimento de produto ou de serviço ao fornecimento de outro produto ou serviço, bem como, sem justa causa, a limites quantitativos (Artigo 39, inciso I, do Código de Defesa do Consumidor).

Observação: com a venda casada, o fornecedor geralmente almeja promover a venda de outro produto ou serviço que não solicitado pelo consumidor. Direcionando, assim, a venda de um determinado produto ou serviços principais como acessórios à venda principal. Entende-se que, por meio desta prática, feremse os seguintes direitos: liberdade de escolha e igualdade nas contratações (vejase, art. 6⿳.丷, inciso Il do Código de Defesa do Consumidor).

Como exemplos de venda casada citam-se os seguintes: a) adquirir cartão de crédito como condição para contratar um empréstimo pessoal; e b) condicionar a contratação de serviço de instalação e montagem de bem adquiridos em lojas.

b) Recusa de atendimento: recusar 0 atendimento às demandas dos consumidores, na exata medida de suas disponibilidades de estoque e, ainda, de 
conformidade com os usos e costumes (Artigo 39, inciso II, do Código de Defesa do Consumidor). Exemplo: a recusa de atendimento indevida e injusta de hospital ou plano de saúde.

c) Entrega sem solicitação do consumidor: enviar ou entregar ao consumidor, sem solicitação prévia, qualquer produto ou fornecer qualquer serviço (Artigo 39, III do Código de Defesa do Consumidor). Exemplo: envio de cartão de crédito não solicitado pelo consumidor.

d) Excepcional vulnerabilidade: prevalecer-se da fraqueza ou ignorância do consumidor, tendo em vista sua idade, saúde, conhecimento ou condição social, para impingir-Ihe seus produtos ou serviços (Artigo 39, inciso IV, do Código de Defesa do Consumidor). Exemplo: a empresa que direciona seus produtos a moradores ou grupos de pessoas com capacidade limitada, tais como crianças, idosos ou deficientes que notoriamente são incapazes de calcular os prejuízos que parcelas e juros podem vir a acarretar.

e) Normas técnicas: colocar, no mercado de consumo, qualquer produto ou serviço em desacordo com as normas expedidas pelos órgãos oficiais competentes ou, se normas específicas não existirem, pela Associação Brasileira de Normas Técnicas ou outra entidade credenciada pelo Conselho Nacional de Metrologia, Normalização e Qualidade Industrial (Conmetro) (Artigo 39, inciso VIII, do Código de Defesa do Consumidor). Exemplo: produtos oferecidos sem a devida observância das normas técnicas ou, ainda, em teste.

f) Recusa da venda: recusar a venda de bens ou a prestação de serviços diretamente a quem se disponha a adquiri-los mediante pronto pagamento, ressalvados os casos de intermediação regulados em leis especiais (Artigo 39, inciso IX, do Código de Defesa do Consumidor);

g) Elevação de preços: elevar, sem justa causa, o preço de produtos ou serviços (Artigo 39, inciso ,X do Código de Defesa do Consumidor).

h) A não entrega prévia de orçamento: orçamento prévio discriminando o valor da mão-de-obra, dos materiais e 
equipamentos a serem empregados, as condições de pagamento, bem como as datas de início e término dos serviços". (Artigo 40 do Código de Defesa do Consumidor).

i) Desrespeito e inobservância de preços tabelados:

[...] no caso de fornecimento de produtos ou de serviços sujeitos ao regime de controle ou de tabelamento de preços, os fornecedores deverão respeitar os limites oficiais sob pena de não o fazendo, responderem pela restituição da quantia recebida em excesso, monetariamente atualizada, podendo o consumidor exigir à sua escolha, o desfazimento do negócio, sem prejuízo de outras sanções cabíveis. (Artigo 41 do Código de Defesa do Consumidor).

j) Publicidade abusiva e discriminatória:

É abusiva, dentre outras a publicidade discriminatória de qualquer natureza, a que incite à violência, explore o medo ou a superstição, se aproveite da deficiência de julgamento e experiência da criança, desrespeita valores ambientais, ou que seja capaz de induzir o consumidor a se comportar de forma prejudicial ou perigosa à sua saúde ou segurança. (Artigo $37, \S 2^{\circ}$.)

- Publicidade enganosa: aquela capaz de induzir o consumidor a erros. Ela pode ser comissiva, quando afirma algo que, na verdade, não é, ou omissiva, quando não informa sobre algo fundamental (essencial) do produto ou serviço.

- Publicidade abusiva: aquela que fere a vulnerabilidade do consumidor, podendo ser até mesmo verdadeira, mas que, pelos seus elementos ou circunstâncias, ofendem valores básicos de toda a sociedade (ex. discriminação, violência, que explora o medo ou a superstição, a antiambiental, a indutora de insegurança, a que se aproveita da hipossuficiência da criança).

\subsection{PRÁTICAS ABUSIVAS CONTRATUAIS}

Veja-se, a seguir, algumas hipóteses de práticas abusivas contratuais:

a) Não fixação de prazos para o cumprimento das obrigações: deixar de estipular prazo para o cumprimento de sua obrigação ou deixar a fixação de seu 
termo inicial a seu exclusivo critério. (Artigo 39, inciso XII, do Código de Defesa do Consumidor);

b) As hipóteses de nulidade inseridas no artigo 51 do Código de Defesa do Consumidor. A saber, cláusulas contratuais que:

- impossibilitem, exonerem ou atenuem a responsabilidade do fornecedor por vícios de qualquer natureza dos produtos e serviços ou impliquem renúncia ou disposição de direitos. Nas relações de consumo entre o fornecedor e o consumidor pessoa jurídica, a indenização poderá ser limitada, em situações justificáveis;

- subtraiam ao consumidor a opção de reembolso da quantia já paga, nos casos previstos no Código de Defesa do Consumidor;

- transfiram responsabilidades a terceiros;

- estabeleçam obrigações consideradas iníquas, abusivas, que coloquem o consumidor em desvantagem exagerada, ou sejam incompatíveis com a boa-fé ou a equidade;

- estabeleçam inversão do ônus da prova em prejuízo do consumidor;

- determinem a utilização compulsória de arbitragem;

- imponham representante para concluir ou realizar outro negócio jurídico pelo consumidor;

- deixem ao fornecedor a opção de concluir ou não o contrato, embora obrigando o consumidor;

- permitam ao fornecedor, direta ou indiretamente, a variação do preço de maneira unilateral;

- autorizem o fornecedor a cancelar o contrato unilateralmente, sem que igual direito seja conferido ao consumidor;

- obriguem o consumidor a ressarcir os custos de cobrança de sua obrigação, sem que igual direito the seja conferido contra o fornecedor;

- autorizem o fornecedor a modificar unilateralmente o conteúdo ou a qualidade do contrato, após sua celebração;

- infrinjam ou possibilitem a violação de normas ambientais;

- estejam em desacordo com o sistema de proteção ao consumidor; e 
- possibilitem a renúncia do direito de indenização por benfeitorias necessárias.

Presume-se exagerada, entre outros casos, a vontade que:

I- ofende os princípios fundamentais do sistema jurídico a que pertence;

II- restringe direitos ou obrigações fundamentais inerentes à natureza do contrato, de tal modo a ameaçar seu objeto ou equilíbrio contratual;

III - mostra-se excessivamente onerosa para o consumidor, considerando-se a natureza e conteúdo do contrato, o interesse das partes e outras circunstâncias peculiares ao caso.

A nulidade de uma cláusula contratual abusiva não invalida o contrato, exceto quando de sua ausência, apesar dos esforços de integração decorrerem ônus excessivos a qualquer das partes.

É facultado a qualquer consumidor ou entidade que o represente requerer ao Ministério Público que ajuíze a competente ação para ser declarada a nulidade de cláusula contratual que contrarie o disposto no Código de Defesa do Consumidor ou de qualquer forma não assegure o justo equilíbrio entre direitos e obrigações das partes.

\subsection{PRÁTICAS ABUSIVAS PÓS-CONTRATUAIS}

Pós-contratuais são aquelas práticas surgidas após se concretizar o contrato. Exemplos:

a) Vantagem excessiva: exigir do consumidor vantagem manifestamente excessiva (Artigo 39, inciso V, do Código de Defesa do Consumidor);

b) Orçamento prévio: executar serviços sem a prévia elaboração de orçamento e autorização expressa do consumidor, ressalvadas as decorrentes de práticas anteriores entre as partes (Artigo 39, inciso VI, do Código de Defesa do Consumidor); 
c) Informação depreciativa: repassar informação depreciativa, referente a ato praticado pelo consumidor no exercício de seus direitos (Artigo 39, inciso VII, Código de Defesa do Consumidor);

d) Falta de prazo: deixar de estipular prazo para o cumprimento de sua obrigação ou deixar a fixação de seu termo inicial a seu exclusivo critério (Artigo 39, inciso XII, do Código de Defesa do Consumidor);

e) Reajuste de preços: aplicar fórmula ou índice de reajuste diverso do legal ou contratualmente estabelecido (Artigo 39, inciso XIII, do Código de Defesa do Consumidor).

f) Exposição a ridículo do consumidor na cobrança de débitos: "Na cobrança de débitos, o consumidor inadimplente não será exposto a ridículo, nem será submetido a qualquer tipo de constrangimento ou ameaça". (Artigo 42 do Código de Defesa do Consumidor)

g) Falta de peças de reposição: os fabricantes e importadores deverão assegurar a oferta de componentes e peças de reposição enquanto não cessar a fabricação ou importação do produto. Cessadas a produção ou importação, a oferta deverá ser mantida por período razoável de tempo, na forma da lei. (Artigo 32 do Código de Defesa do Consumidor)

h) Cobrança de quantia indevida: "O consumidor cobrado em quantia indevida tem direito à repetição do indébito, por valor igual ao dobro do que pagou em excesso, acrescido de correção monetária e juros legais, salvo hipótese de engano justificável". (Artigo 42, parágrafo único do Código de Defesa do Consumidor).

Além de sanções administrativas (por exemplo, a cassação de licença, a interdição e a suspensão de atividade, a intervenção administrativa) e penais (Capítulos XII e XIII), as práticas abusivas engendram o dever de reparar, originando a indenização pelos danos causados, inclusive os morais. Conforme o art. 6‥, é direito básico do consumidor VII: o acesso aos órgãos judiciários e administrativos com vistas à prevenção ou reparação de danos patrimoniais e morais, individuais, 
coletivos ou difusos, assegurada a proteção Jurídica, administrativa e técnica aos necessitados.

O Código de Defesa do Consumidor traz expressamente em seu Artigo 39 um rol exemplificativo de práticas abusivas, ou seja, não trata de todas as práticas que são consideradas abusivas:

Art. 39. É vedado ao fornecedor de produtos ou serviços, dentre outras práticas abusivas: I - condicionar o fornecimento de produto ou de serviço ao fornecimento de outro produto ou serviço, bem como, sem justa causa, a limites quantitativos; II - recusar atendimento às demandas dos consumidores, na exata medida de suas disponibilidades de estoque, e, ainda, de conformidade com os usos e costumes; III - enviar ou entregar ao consumidor, sem solicitação prévia, qualquer produto, ou fornecer qualquer serviço; IV - prevalecer-se da fraqueza ou ignorância do consumidor, tendo em vista sua idade, saúde, conhecimento ou condição social, para impingirIhe seus produtos ou serviços; $V$ - exigir do consumidor vantagem manifestamente excessiva; VI - executar serviços sem a prévia elaboração de orçamento e autorização expressa do consumidor, ressalvadas as decorrentes de práticas anteriores entre as partes; VII - repassar informação depreciativa, referente a ato praticado pelo consumidor no exercício de seus direitos; VIII - colocar, no mercado de consumo, qualquer produto ou serviço em desacordo com as normas expedidas pelos órgãos oficiais competentes ou, se normas específicas não existirem, pela Associação Brasileira de Normas Técnicas ou outra entidade credenciada pelo Conselho Nacional de Metrologia, Normalização e Qualidade Industrial (Conmetro); IX - recusar a venda de bens ou a prestação de serviços, diretamente a quem se disponha a adquiri-los mediante pronto pagamento, ressalvados os casos de intermediação regulados em leis especiais; $X$ - elevar sem justa causa 0 preço de produtos ou serviços; XI - Dispositivo incluído pela MPV no 1.890-67, de 22.10.1999, transformado em inciso XIII, quando da conversão na Lei ํㅜ 9.870, de 23.11.1999; XII - deixar de estipular prazo para o cumprimento de sua obrigação ou deixar a fixação de seu termo inicial a seu exclusivo critério; XIII - aplicar fórmula ou índice de reajuste diverso do legal ou contratualmente estabelecido. (Leil № 8.078, de 11 de setembro de 1990.)

Na parte doutrinária, há uma ligação entre a prática de atos abusivos com a teoria do abuso do direito, regulamentada no Código Civil de 2002, no Artigo 187: "Também comete ato ilícito o titular de um direito que, ao exercê-lo, excede manifestamente os limites impostos pelo seu fim econômico ou social, pela boa-fé ou pelos bons costumes." (Lei №. 10.406, de 10 de janeiro de 2002.) 


\section{OS CONFLITOS DERIVADOS DAS RELAÇÕES DE CONSUMO}

Define-se o termo "conflito" como o choque (ou colisão) de interesses que se origina na relação de consumo. Se, por um lado, o interesse principal do fornecedor (empresário) é o lucro, por outro, o interesse do consumidor é a satisfação de uma necessidade material ou espiritual, por meio do consumo. Vemos assim, o Conflito de interesses: lucros versus "necessidade (consumo)" como a causa principal dos conflitos.

Os conflitos jurídicos geralmente têm como causa as injustiças cometidas contra os consumidores, e deles derivam-se reclamações por razão dos preços, da qualidade, da forma e do lugar de entrega e demais condições não cumpridas no contrato que geram danos para os consumidores.

Considera-se o consumo como a última fase do processo de produção que gera direitos e deveres, cuja via de existência é o conjunto de relações que se constituem entre $\mathrm{o}$ produtor e $\mathrm{o}$ consumidor, a partir das próprias necessidades sociais e da distribuição dos bens materiais. Em verdade, a atividade de consumo repercute na comercialização dos produtos, momento em que os cidadãos procuram adquirir bens ou serviços com o objetivo de satisfazer suas necessidades. Assim, estabelecem-se relações contratuais das quais surgem conflitos muitas vezes não resolvidos pelo Direito vigente.

Dessa maneira, Víctor Hugo Lares Romero (1991, p. 24), ao referir-se aos conflitos jurídicos derivados das relações de consumo, observa que "pode-se afirmar que os abusos dos quais o consumidor é vítima têm tido sua origem no sistema da livre concorrência, onde os conflitos nascidos de tais relações não encontram solução de acordo com as regras jurídicas tradicionais".

Dentre as causas que geram conflitos jurídicos na relação fornecedor consumidor pode-se destacar a falta de escolha (vontade limitada) dos consumidores, quando estes são obrigados a adquirir um produto não desejado com outros desejados, ou quando algumas das cláusulas (abusivas) já estão preestabelecidas e não existe possibilidade de decisão sobre elas. 
O mesmo ocorre em relação à fraude; é perniciosa a ausência de garantia, a falta de informação ou a informação enganosa, mediante a qual o produtor (fornecedor) tem como objetivo demonstrar a boa qualidade de seus produtos e serviços e não garantir a informação para fazer pública as deficiências, defeitos ou inconvenientes que possam apresentar-se ao adquirir tais produtos ou serviços, questão que coloca em estado desfavorável os consumidores.

\subsection{PARA UMA TIPOLOGIA DE CONFLITOS}

Os conflitos nascidos da relação de consumo aparecem nas suas diversas fases, a saber:

a) Pré-contratual: fase onde podem acontecer as diversas ações ou as omissões acometidas pelo fornecedor, também chamadas de práticas abusivas (por exemplo, o envio de um cartão de crédito não solicitado);

b) Contratual: origina-se da compra ou contratação de produto e serviços (por exemplo, a existência de cláusulas que exoneram a responsabilidade do fornecedor derivada da venda de alimentos, brinquedos, veículos ou da contratação de serviços);

c) Pós-contratual: da qual resulta a negação de direitos derivados dos contratos consumidores (por exemplo, a falta de peças de reposição e demais consequências inesperadas que resultam do serviço de saúde, transporte, etc.).

Inúmeros são os conflitos jurídicos surgidos da relação de consumo. Assim, por exemplo, pode-se citar aqueles surgidos das agressões contra a saúde do consumidor, gerados, majoritariamente pela falta de informação ou pela desinformação, de parte do fornecedor, ao colocar seus produtos no mercado.

Alguns doutrinadores destacam diversos exemplos de ações ou de omissões das quais o consumidor pode ser vítima. Um dos exemplos mais chocantes na história da sociedade de consumo, especificamente norte-americana, refere-se à irresponsabilidade do Laboratório Merrell Company, acontecido no final da década de 50 , quando, ao lançar no mercado um novo sedativo "talidomida", sem fazer 
referência às restrições para o caso das mulheres gestantes, provocou a afetação de mais de 10 mil bebês em mais de 20 países. (RIOS, 1994, p. 12)

A publicidade enganosa por omissão é uma das causas mais significativas dos prejuízos ocasionados aos consumidores. Igualmente, dentre as injustiças derivadas das relações de consumo coloca-se, também, a questão dos preços elevados.

As reclamações mais frequentes referem-se à falta de qualidade dos serviços prestados fundamentalmente pelas operadoras ou companhias telefônicas, assim como inúmeros casos de prazos de validade vencidos em alimentos e medicamentos colocados no mercado de consumo.

Outros casos não menos importantes são divulgados pelos Procons. Os mais alarmantes são os relacionados ao Sistema Nacional de Saúde: a venda de medicamentos falsificados, o exercício ilícito da profissão médica, importação e venda de produtos de péssima qualidade, etc.

Contudo, para melhor compreender esta problemática, veja-se as estatísticas publicadas anualmente pelo Procon (dados sobre o atendimento) nas diversas áreas das quais também resultam reclamações.

\section{A EDUCAÇÃO E A INFORMAÇÃO COMO DIREITOS BÁSICOS DO CONSUMIDOR}

Direitos básicos dos consumidores são os interesses mínimos, materiais ou instrumentais, relacionados a direitos fundamentais universalmente consagrados que, diante da sua relevância social e econômica, pretendeu o legislador ver expressamente tutelados: as linhas mestras do ideal a ser seguido na proteção física, psíquica e econômica dos consumidores, bem como de certas garantias instrumentais mínimas, capazes de conferir efetividade à tutela jurídica do consumidor. (CAVALIERI FILHO, 2010, p. 82) 
Se, de um lado, continua o citado autor, a legislação prevê direitos básicos para os consumidores, de outro, cria deveres igualmente básicos para os fornecedores. Não precisa o consumidor cobrar do fornecedor o cumprimento de sua obrigação legal; ao contrário, a posição do consumidor, agora, é bastante confortável, já que, ainda que desconheça os seus direitos, mesmo assim tem o fornecedor o dever de agir conforme determina a lei. Por exemplo, mesmo que o consumidor pudesse desconhecer o seu direito básico à proteção de sua vida, saúde e segurança contra os riscos provocados por práticas no fornecimento de produtos e serviços considerados perigosos ou nocivos, ainda assim tem o fornecedor o dever de respeitá-lo, sob pena de responsabilidade. O mesmo raciocínio vale para todos os demais direitos básicos. O espírito da lei não é privilegiar o consumidor, mas, sim, dotá-lo de recursos materiais e instrumentais que o coloquem em posição de equivalência com o fornecedor, visando ao equilíbrio e à harmonia da relação de consumo. (CAVALIERI FILHO, 2010, p. 84)

São, conforme a doutrina nacional, direitos básicos do consumidor consagrados no art. 6º do Código de Defesa do Consumidor:

\begin{abstract}
Dos Direitos Básicos do Consumidor. Art. 6ํㅗ̃o direitos básicos do consumidor: I - a proteção da vida, saúde e segurança contra os riscos provocados por práticas no fornecimento de produtos e serviços considerados perigosos ou nocivos; II - a educação e divulgação sobre o consumo adequado dos produtos e serviços, asseguradas a liberdade de escolha e a igualdade nas contratações; III - a informação adequada e clara sobre os diferentes produtos e serviços, com especificação correta de quantidade, características, composição, qualidade e preço, bem como sobre os riscos que apresentem; [...].
\end{abstract}

Como prescrito no parágrafo único do artigo $7^{\circ}$. do referido Código, tais direitos não excluem outros decorrentes de tratados ou convenções internacionais de que o Brasil seja signatário, da legislação interna ordinária, de regulamentos expedidos pelas autoridades administrativas competentes, bem como dos que derivem dos princípios gerais do direito, analogia, costumes e equidade.

É preciso, contudo, estudar cada direito separadamente: 
a) Vida, saúde e segurança. Assegurar a proteção de tais direitos é assegurar a realização de valores supremos do ser humano. Diz-se dos direitos mais básicos e mais importantes dos direitos do consumidor, "ainda mais tendo em vista que nossa sociedade é uma sociedade de risco, muitos produtos, muitos serviços e mesmo práticas comerciais são efetivamente perigosas e danosas para os consumidores". (BENJAMIN, 2010, p. 67)

Trata-se de direitos básicos também prescritos nos artigos $8^{\circ}$. a 17 do Código de Defesa do Consumidor. Vê-se a proteção do valor vida que abrange a segurança e a saúde contra os riscos provocados por práticas no fornecimento de produtos e serviços considerados perigosos ou nocivos, como o primeiro direito derivado da relação de consumo.

b) Liberdade de escolha. Assegurar a liberdade de escolha é assegurar que - consumidor possa decidir perante as técnicas de vendas agressivas constantemente usadas no mercado de consumo. Vê-se, igualmente, esse direito inserido na proteção pré-contratual (art. 30) e contratual (art. 46 e seguintes), resultado da educação (consciência) e divulgação sobre o consumo adequado dos produtos e serviços.

A educação para o consumo também é um direito básico do consumidor, que objetiva assegurar a liberdade de escolha e a igualdade nas contratações.

c) Informação. Diz-se de um direito básico correlacionado ao princípio da vulnerabilidade do consumidor (art. $4^{\circ}{ }^{\circ}$, inciso I) e a necessidade da presença do Estado no mercado para proteger os sujeitos de direito (art. 4ํ․, inciso II). Precisa-se, logo, da informação adequada e clara sobre os diferentes produtos e serviços, com especificação correta de quantidade, características, composição, qualidade e preço, bem como sobre os riscos.

Diz-se da oportunidade de o consumidor conhecer o contrato previamente, ficando o fornecedor obrigado a fazê-lo, antecipadamente e com absoluta transparência. Desta forma, cabe ao fornecedor dar cabal informação sobre o produto ou serviço.

Contudo, junto à obrigação pré-contratual de informar adequadamente sobre os bens colocados no mercado (art. 6., inciso III, e art. 31), os contratos não 
obrigam os consumidores se não Ihes for dada a oportunidade de tomar conhecimento prévio do conteúdo ou se estiverem redigidos de forma complicada (art. 46). Ademais, os contratos de adesão devem possuir palavras claras e letras legíveis (tamanho 12), de modo a facilitar a compreensão do seu conteúdo pelo consumidor. As cláusulas que imponham obrigações ao consumidor devem ser regidas com destaque (art. 54, § $4^{\circ}$.). (BENJAMIN, 2010, p. 317)

Desta forma, cláusulas impositivas de obrigações devem ser destacadas. Assim sendo, o legislador prescreveu a possibilidade de considerar nulas (nulidade absoluta ou de pleno direito) as cláusulas que agridam os direitos do consumidor e outros bens juridicamente protegidos.

Desta forma, o juiz, ao analisar o contrato de consumo, pode negar eficácia a algumas dessas cláusulas. (BENJAMIN, 2010, p. 317)

Quanto às práticas comerciais, determinam-se regras especificamente para equiparar (igualar) os consumidores e toda pessoa exposta a esta prática.

A partir do artigo 31 (norma de tipo operativa), estabelecem-se requisitos que têm de ser cumpridos para facilitar a execução dos atos jurídicos (contratos de consumo) e evitar maiores prejuízos para os consumidores.

A oferta de produtos ou serviços, por exemplo, devem assegurar informações corretas, claras, precisas, em língua portuguesa, sobre suas características, qualidades, quantidade, composição, preço, garantia, prazos de validade e origem, entre outros dados; assim como sobre os riscos que apresentam para a saúde e a seguridade dos consumidores.

Diz-se dos métodos comerciais coercitivos ou desleais, bem como contra práticas e cláusulas abusivas ou impostas no fornecimento de produtos e serviços.

As cláusulas abusivas são aquelas previstas no art. 51, com XVI incisos exemplificativos; produzem nulidade absoluta, sendo imprescritível o prazo para 0 pedido judicial de sua anulação. São elas:

a) as cláusulas que autorizem o fornecedor a não indenizar em caso de vício ou defeito;

b) a subtração ao consumidor do direito de reembolso das quantias pagas; 
c) a transferência de responsabilidade a terceiros;

d) as obrigações iníquas e vantagem exagerada para o fornecedor;

e) a incompatibilidade com a boa fé e com a equidade;

f) a inversão do ônus da prova em favor do fornecedor;

g) as que imponham arbitragem compulsória;

h) as que imponham representante do consumidor, dentre os funcionários do fornecedor;

i) as que dêem opção ao fornecedor em concluir o negócio;

j) as que estabeleçam possibilidade de alteração unilateral do preço, pelo fornecedor;

k) as que autorizem o fornecedor a cancelar o contrato unilateralmente;

l) as que estabeleçam ressarcimento unilateral do custo de cobrança;

m) a modificação unilateral do contrato pelo fornecedor;

n) as que violem normas ambientais;

o) as que estejam em desacordo com o sistema do consumidor;

p) as que estabeleçam renúncia à indenização por benfeitorias.

Vê-se, assim, o caráter aberto e exemplificativo do art. 51. A sanção para as cláusulas abusivas no Código de Defesa do Consumidor é indicada expressamente ao prescrever-se a nulidade de pleno direito no próprio artigo 51 .

Os fabricantes e importadores deverão assegurar a oferta de componentes e peças de reposição enquanto não cesse a fabricação ou importação do produto. Cessando a produção ou importação, a oferta deverá ser mantida por período razoável de tempo.

Quanto à oferta ou à venda por telefone ou reembolso postal, devem constar tanto o nome do fabricante como o seu endereço na embalagem, na publicidade, etc.

Quem oferece serviços é solidariamente responsável pelos atos de seus representantes autônomos. No caso de inadimplemento, o consumidor poderá escolher livremente entre:

a) exigir o cumprimento forçoso da obrigação, nos termos da oferta; 
b) aceitar outro produto ou prestação de serviço equivalente;

c) rescindir o contrato, com direito à restituição da quantia eventualmente antecipada, monetariamente, as perdas e danos.

Uma vez aprovada pelo consumidor, a oferta obriga os contratantes e só pode ser alterada mediante livre negociação. O consumidor não responde por qualquer gravame nascente da contratação de serviços de terceiros não previstos na oferta. No caso em que sejam oferecidos produtos ou serviços sujeitos ao regime de controle ou de tabelas de preços, deverão ser respeitados os limites oficiais, em caso contrário responder-se-á pela restituição da quantia recebida em excesso, monetariamente atualizada, podendo o consumidor exigir, à sua escolha, a resolução do negócio, sem prejuízo de outras sanções.

d) Transparência e boa-fé. Proíbe-se o abuso de direito e prescreve-se a transparência e a boa-fé como direitos dos consumidores, que realmente são princípios que balizam as relações de consumo. Assim, tais princípios e direitos objetivam a proteção contra a publicidade enganosa ou desleal, bem como contra práticas e cláusulas aos produtos e serviços.

A publicidade deve ser executada de forma que o consumidor, fácil e imediatamente, possa identificá-la; portanto, quem oferta um serviço deve manter em seu poder, para a informação dos legítimos interessados, os dados técnicos e científicos que sustentam a mensagem.

Por sua vez, quem oferece o serviço está obrigado a entregar ao consumidor a descrição prévia do valor da mão de obra, dos materiais e dos equipamentos a serem empregados, as condições de pagamento, a data de início e término dos serviços. Salvo estipulação em contrário, o valor apresentado (oferta) terá validade por um prazo de dez dias, contados a partir de seu recebimento pelo consumidor.

e) Proteção contratual. Diz-se da possibilidade de modificação das cláusulas contrárias aos atos que se tornem excessivamente onerosas (a revisão por onerosidade excessiva): o direito à revisão contratual "por quebra da base do negócio, em face de fatos supervenientes que as tornem excessivamente onerosas". (BENJAMIN, 2010, p. 70) 
O legislador brasileiro, igualmente, decidiu regrar a proteção contratual e atenuar as consequências negativas e desvantajosas que geram a adesão para o consumidor, regulamentando a maneira que têm de ser interpretadas as cláusulas nestes tipos de contratos, estabelecendo-se nos artigos 46 e 47 do Código de Defesa do Consumidor que os contratos regulamentadores de relações de consumo não obrigam os consumidores se não lhes é dada a oportunidade de tomar conhecimento prévio de seu conteúdo, ou se os respectivos instrumentos dificultam a compreensão de seu sentido e alcance.

As cláusulas contratuais serão interpretadas da maneira mais favorável ao consumidor, segundo se estabelece no art. 47 do próprio Código: As cláusulas contratuais serão interpretadas de maneira mais favorável ao consumidor. Note-se aqui uma regra própria da hermenêutica jurídica com a qual se possibilita a interpretação e aplicação do direito.

f) Prevenção e reparação de danos morais e materiais. Assegura-se o direito à prevenção e reparação de danos aos consumidores, possível pela desconsideração da personalidade jurídica, permitindo-se "a quebra de dogma da separação patrimonial entre a pessoa jurídica e seus sócios" (BENJAMIN, 2010, p. 70), conforme prescrito no artigo 28 do Código de Defesa do Consumidor. Importa aqui refletir acerca da existência de uma efetiva prevenção e reparação de danos patrimoniais e morais, individuais, coletivos e difusos. Mediante normas de ordem pública atribuem-se faculdades aos juízes, pelas quais poderão desconsiderar a personalidade jurídica das sociedades, quando em detrimento do consumidor existir abuso do direito, excesso de poder, infração da lei, fato ou ato ilícito, ou violação dos estatutos ou contrato social.

g) Acesso à justiça e inversão do ônus da prova. Assegurar o acesso à justiça é assegurar a inclusão social e jurídica, isto é, assegurar o:

[...] acesso à justiça e aos órgãos administrativos em geral, inclusive às agências que controlam os serviços ex-públicos e aos órgãos de defesa do consumidor, Procons etc., sempre com vistas à prevenção e reparação de danos, individuais e coletivos, aos consumidores. (BENJAMIN, 2010, p. 74). 
Menciona-se, todavia, da defesa dos direitos, inclusive com a inversão da carga da prova, a seu favor, no processo civil, quando a critério do juiz, e segundo as regras ordinárias de experiência, perante a impossibilidade evidente de poder provar ou de se tornar custoso e difícil para o consumidor hipossuficiente.

As condições de vulnerabilidade e (ou) hipossuficiência permitem e autorizam a inversão do ônus da prova, a favor do consumidor, no processo civil, conforme critério do juiz.

Consideram-se nulas de pleno direito, entre outras, as cláusulas contratuais relativas ao fornecimento de produtos e serviços que estabeleçam inversão do ônus da prova em prejuízo do consumidor. (Veja-se art. 51, inciso IV)

A disciplina relativa ao ônus processual é contida no art. 333 do Código de Processo Civil e no s arts. 6‥, inciso VIII, e 38 do Código de Defesa do Consumidor.

O art. 333 do Código de Processo Civil prescreve ser ônus do autor a prova de fatos constitutivos do seu direito e, de outro lado, ônus do réu a demonstração de existência de fato impeditivo, modificativo ou extintivo do direito do autor. O parágrafo único e os dois incisos do art. 333 possibilitam que as partes, por meio de disposição contratual, distribuam de maneira diversa o ônus da prova, salvo quando recair sobre direito indisponível da parte ou tornar excessivamente difícil a uma parte o exercício do direito. No Código de Defesa do Consumidor, artigo 6º, inciso VIII, inclui-se como um direito básico do consumidor:

[...] a facilitação da defesa de seus direitos, inclusive com a inversão do ônus da prova, a seu favor, no processo civil, quando, a critério do juiz, for verossímil a alegação ou quando for ele hipossuficiente, segundo as regras ordinárias de experiências.

Igualmente, conforme 0 art. 38 do citado texto legal: "O ônus da prova da veracidade e correção da informação ou comunicação publicitária cabe a quem as patrocina".

Conclui-se que a inversão do ônus da prova estabelecida no Código de Defesa do Consumidor não pode ser alterada por disposição contratual, até porque, as normas do referido Código são de ordem pública e interesse social (art. 1ํ․) e, 
portanto, inafastáveis por acordo de vontade entre consumidor e fornecedor. (BENJAMIN, 2010, p. 347)

Todavia, além da inversão do ônus da prova, fala-se do protecionismo do consumidor, prescrito na regra de hermenêutica contida no art. 47, que estabelece: "As cláusulas contratuais serão interpretadas de maneira mais favorável ao consumidor".

h) Serviços públicos adequados e eficazes. Diz-se de um direito, também prescrito no art. 22 do Código de Defesa do Consumidor e, também ligado ao princípio de "eficiência" constitucionalmente reconhecido no art. 37 da Constituição.

Quanto à eficácia na prestação dos serviços públicos, deve-se conferir por analogia o estabelecido no art. 37 da Constituição. Vale, igualmente, fazer uma remissão à leitura da seção anterior que trata dos serviços públicos (essenciais ou não).

\section{CONSIDERAÇÕES FINAIS}

A relação de consumo é uma relação de confiança, motivo pelo qual as partes devem ter consciência do papel que desempenham no plano das relações socioeconômicas.

Mas, infelizmente, contamos com a triste realidade, onde os consumidores, situados numa relação de desigualdade, sofrem agressões diversas a seus direitos e nem sempre contam com as informações adequadas para a defesa dos seus direitos.

O Código de Defesa do Consumidor veio para tentar apaziguar essa desigualdade de poder, ao criar normas que proíbam determinadas práticas no mercado de consumo, porém, nem sempre consegue blindar o consumidor contra elas.

Sabe-se, todavia, que os fornecedores, de forma voluntária e premeditada, desenvolvem práticas comerciais que se sabem abusivas por agredir os direitos dos 
consumidores consagrados na Constituição e no Código de Defesa do Consumidor e, na maioria das vezes, atribuem a culpa na economia, na competitividade do mercado, dentre outras alegações das quais disfarçam essas práticas, fazendo assim com que o consumidor seja levado ao erro e, muitas vezes geram prejuízos ao seu patrimônio.

As práticas comerciais abusivas são imorais e opressoras, indo contra os padrões de ética da sociedade, vale ressaltar que as mesmas não necessariamente têm que produzir um dano para serem consideradas abusivas. A partir da constatação de que o titular de um direito subjetivo pode fazer abuso do mesmo durante o seu exercício, levou o legislador a classificar algumas práticas como abusivas.

Importa, assim, a educação dos fornecedores, uma educação que possibilite a edificação moral e a consequente informação dos consumidores sobre as empresas majoritariamente reclamadas, possibilitando, com isso, a tomada de consciência consumerista em face da não contratação de serviços e produtos dos fornecedores infratores.

\section{REFERÊNCIAS}

BENJAMIN, Antônio Herman. Código Brasileiro de Defesa do Consumidor comentado pelos autores do anteprojeto. 8. ed. Rio de Janeiro: Forense Universitária, 2004, p. 242.

; MARQUES, Claudia Lima; BESSA, Leonardo Roscoe. Manual de direito do consumidor. 3. ed. ver., atual. e ampl. São Paulo: Rt, 2010, p. 251-252.

BITTAR, Carlos Alberto. Direitos do Consumidor: Código defesa do consumidor. 7.ed. Rio de Janeiro: Forense. Rio de Janeiro, 2011

CAVALIERI FILHO, Sérgio. Programa de Direito do Consumidor. 3. ed. São Paulo: Atlas, 2011.

GARCIA, Leonardo de Medeiros. Direito do consumidor: código comentado, jurisprudência, doutrina, questões, Decreto n. 2.181/97. 6. Ed. Ver., ampl. Pelas Leis 11.989/2009 e 12.039/2009. Niterói: Ímpetus, 2010. 
GIANCOLI, Brunno Pandori; ARAÚJO JUNIOR, Marco Antônio. Direito do Consumidor. 3. ed. São Paulo: Rt, 2012.

LARES Romero, Victor Hugo. El Direito de Proteção a los Consumidores en México. Umiversidad Autónoma Metropolitana. Azcapotzalco, México, D. F.,1991.

MARTINS, Plínio Lacerda. O Abuso nas relações de consumo e o princípio da boa-fé. Rio de Janeiro: Forence, 2002

MARQUES, Claudia Lima. Introdução ao Direito do Consumidor. In BENJAMIN, Antônio Herman V; MARQUES, Claudia Lima; BESSA, Leonardo Roscoe. Manual de direito do consumidor. 3. ed. ver., atual. e ampl. São Paulo: Rt, 2010, p. 29-31.

NUNES, Rizzatto. Curso de Direito do Consumidor. 7. ed. São Paulo: Saraiva, 2012.

Curso de direito do consumidor: com exercícios. 6. ed. ver., modif. e atual. São Paulo: Saraiva, 2011.

2005.

. Curso de Direito do Consumidor: com exercícios. São Paulo: Saraiva,

PEREIRA JUNIOR, Nilton Nunes. O Código de defesa do consumidor e as operações financeiras. Rio de Janeiro: Forense, 2006

RIOS, Josué, Marilena Lazzarini, Vidal Serrano Jr. O que é Defesa do consumidor. Coleção Primeiros Passos. São Paulo: Brasiliense, 1994.

ROSCOE BESA, Leonardo. Proteção Contratual. In BENJAMIN, Antônio Herman V; MARQUES, Claudia Lima; BESSA, Leonardo Roscoe. Manual de direito do consumidor. 3. ed. ver., atual. e ampl. São Paulo: Rt, 2010.

SERRANO, Pablo Jiménez. Direito do Consumido: sentido, alcance e efetividade (livro eletrônico), editora Jurismestre, Rio de Janeiro, 2015. 